\title{
Possible Prophylactic Role of Querctine on Cisplatin-Induced Myocardial Toxicity in Adult Male Albino Rat: Histological and Immunohistochemical Study
}

\author{
MOGEDA M. NASRALLA, M.D. \\ The Department of Anatomy and Embryology, Faculty of Medicine, Cairo University
}

\begin{abstract}
Background: Cisplatin is an effective chemotherapeutic agent used in treatment of solid tumors. Cardiotoxicity is one of the major side effect frequently observed after administration of cisplatin. Quercetin, an important dietary flavonoid present in several fruits and vegetables, exhibits antioxidant, antiinflammatory and anti-cancer properties.
\end{abstract}

Aim of Work: The present work was designed to study the histological changes in the heart of the adult male albino rat, following administration of cisplatin and the possible prophylactic role of querectine.

Material and Methods: Forty adult male albino rats were used in this study. They were divided into four groups, ten rats each; Group I (normal control) received nothing, Group II (sham control): Received a daily oral dose of one $\mathrm{ml}$ of normal saline via gastric gavage. Group III (CP): Received intraperitoneal single injection of cisplatin at $15 \mathrm{mg} / \mathrm{kg}$ dose on the eighth day. Group IV: Querectine has been orally administered at $30 \mathrm{mg} / \mathrm{kg} / \mathrm{day}$ dose for one month beginning seven days prior to single cisplatin injection. At the end of experiments the heart was removed, and prepared for light and electron microscopic studies.

Results: Cisplatin treated animals (Group III) showed structural changes in the myocardium in the form of focal lesions in many sections and fragmentation of muscle fibers. By electron microscopic examination, mitochondria revealed variability in size and shape, enlargement (ballooning) with disturbed cristal pattern. Immunohistochemical study of myocardium of Group III animals stained with anti- $\alpha$-smooth muscle actin antibody showed positive immunoreactivity. Querectine pretreated animals revealed amelioration in histological alterations in the myocardium when compared to cisplatin treated group.

Conclusion: This study demonstrated that querectine had a significant effect in protection of the heart against myocardial histological changes induced by cisplatin.

Key Words: Querectine - Cardio prophylactic - Antioxidant activity-Cisplatin.

Correspondence to: Dr. Mogeda M. Nasralla, The Department of Anatomy and Embryology, Faculty of Medicine, Cairo University

\section{Introduction}

CISPLATIN is an effective chemotherapeutic agent used in treatment of solid tumors of the lung, ovary, testis as well as hematological malignancies [1]. Various studies reported many clinical finding in the heart after cisplatin administration these findings including electrocardiographic changes, arrhythmia, cardiomyopathy and congestive heart failure [2].

Chirino and Pedraza-Chaverri, [3] reported that free oxygen radicals resulted from cisplatin administration play an important role in inducing toxicity. Free oxygen radicals induced by cisplatin produce cellular injury and necrosis via several mechanisms including peroxidation of membrane lipids and proteins and damage of DNA [4]. Devrim et al., [5] and Kuhed et al., [6] reported that in cisplatin treated animals, there was a decrease of the antioxidant enzyme activites (superoxide dismutase, catalase and glutathione perioxidase). All these mechanisms greatly encourage the using of free radical scavengers and antioxidants to counteract cisplatin-induced toxicities $[\mathbf{7 , 8}]$.

Quercetin (3, 3', 4', 5, 7-pentahydroxyflavone), an important dietary flavonoid present in several fruits and vegetables, exhibits antioxidant, antiinflammatory and anti-cancer properties [9]. Quercetin scavenges superoxide anion, singlet oxygen and lipid peroxy radicals [10,11] and inhibits coppercatalysed oxidation [12]. Several reports demonstrate that quercetin scavenges Reactive Oxygen Species (ROS)-induced cardiomyopathy [13,14]. Furthermore,quercetin protects cardiomyocytes from the oxidative stress induced by $\mathrm{H}_{2} \mathrm{O}_{2}$ through its antioxidant activity and it modulates the apoptosis signal transduction pathway [14]. Quercetin was more effective than other flavonoids such as 
naringenin, pycnogenol and trolox, in protecting against daunorubicin-induced cytotoxicity in cardiomyocytes [15]. The present study was performed to elucidate the prophylactic role of querectin in ameliorating the cisplatine induced cardiotoxicity.

The aim of this study was planed to monitor the histological and ultrastructural changes in the myocardium of adult male albino rats following administration of cisplatin and evaluate the possible cardioprotective effect of qurectine against experimental cardiotoxicity induced by cisplatin.

\section{Material and Methods}

\section{Chemicals:}

Cisplatin, in the form of powder, obtained from Bristol-Myers Squibb Company, Each vial containing $10 \mathrm{mg}$ and was given by intraperitonal injection at a dose of $15 \mathrm{mg} / \mathrm{kg}$ body weight [16], solution of of cisplatin was perepared by dilution of $15 \mathrm{mg}$ in $5 \mathrm{ml}$ normal saline to get final concentration 3 $\mathrm{mg} / \mathrm{ml}$. Quercetin powder was obtained from Sigma Chemical Company (St. Louis, MO, USA) and was diluted with $20 \%$ glycerol in $0.9 \%$ normal saline and stored in a dark bottle at $4^{\circ} \mathrm{C}$. The quercetin solution was freshly prepared each week and was given by gavages at a dose $30 \mathrm{mg} / \mathrm{kg}$ body weight [17]. 30mg of qurecetine was diluted in $5 \mathrm{ml}$ (20\% glycerol in $0.9 \%$ normal saline to get final concentration of $6 \mathrm{mg} / \mathrm{ml}$.

\section{Animals:}

Forty adult male albino rats (Sprague Dawly) weighing $180-200 \mathrm{~g}$ were used in the ingoing study. They were obtained from the Animal House, June 2017-Dec. 2017, Faculty of Medicine, Cairo University. The animals were maintained in spacious wire mesh cages, each contained four rats with direct day light and natural ventilation at room temperature and allowed water and food ad libitum. All the animals were treated in accordance to the institutional guidelines for the care and use of laboratory animals.

\section{Experimental design:}

The rats were divided into 4 groups $(n=10$ each):

Group I: Normal control group. (Received nothing).

Group II (sham control): Received a daily oral dose of one $\mathrm{ml}$ of normal saline via gastric gavage.

Group III: Received intraperitoneal single injection of cisplatin at $15 \mathrm{mg} / \mathrm{kg}$ dose on the eighth day [16].
Group IV: Querectine has been orally administered at $30 \mathrm{mg} / \mathrm{kg} /$ day dose for one month beginning seven days prior to single cisplatin injection [17].

After one month from the beginning of the experiment the animals were scarified by over dose of intravenous injection of Phenoparbital $100 \mathrm{mg} / \mathrm{kg}$. Then heart specimens (from the left ventricle) were taken from rats of all groups and subjected to the flowing studies.

I- Light microscopic study: Specimens were fixed in $10 \%$ buffered formol saline and processed for paraffin sections of 5-7 $\mu \mathrm{m}$ thickness, mounted on glass slides. Other sections were mounted on +ve charged slides for immunohistochemistry.

These sections were subjected to the following:

1- H \& E and Masson's trichrome stain.

2- Immunohistochemichal staining for alpha smooth muscle actin $(\alpha-$ SMA).

Primary antibody: Actin, Smooth Muscle Ab1 (Clone 1A4):

It is a Mouse Monoclonal Antibody (Novocastra Lyphilized Corporation laboratories, UK, catalogue number NCL-SMA). It was supplied as $(7.0 \mathrm{ml})$ of antibody $(200 \mathrm{ug} / \mathrm{ml})$ prediluted in $0.05 \mathrm{~mol} / \mathrm{L}$ Tris$\mathrm{HCl}, \mathrm{pH} 7.6$ containing stabilizing protein and $0.015 \mathrm{~mol} / \mathrm{L}$ sodium azide. It was stored at $2-8^{\circ} \mathrm{C}$. No special pretreatment was required for immunohistochemical staining of formalin-fixed tissues.

\section{Detection system for antibody:}

Histostain SP kit (LAB-SA system, Zymed Laboratories Inc, San Francisco, CA 94080, USA, catalogue number 95-9643). It is a broad spectrum detection system that reacts with mouse, rabbit, guinea pig and rat primary antibody. This Histostain SP kit included serum blocking solution, a biotinylated secondary antibody, a horseradish peroxidase streptavidin and a substrate chromogen mixture to demonstrate antigen in cells and tissue.

Histomorphometric study: Using Leica image analysis computer system (soft ware Qwin 500), the following parameters were measured:

A- Area \% of collagen fibers in Masson's Trichrome stained sections was examined by magnification X400 and measured within a field of standard measuring frame this was done in 10 non overlapping microscopic fields of each specimen and their mean values were obtained and subjected to statistical analysis.

B- Area $\%$ of immune reaction of $\alpha$-SMA: Area $\%$ was measured for degree of immune reaction 
of $\alpha$-SMA in anti- $\alpha$-SMA stained sections using an objective lens of magnification $40 \mathrm{x}$ i. e. a total magnification $\mathrm{X} 400$ in 10 random non overlapping fields in each section, inside a standard measuring frame of area (116964.91 $\mu \mathrm{m}^{2}$ ). The total and mean values were obtained and subjected to statistical analysis.

II- Electron microscopic study: Small pieces of the left ventricle was fixed in glutaraledhyde (PH 7.4) in phosphate buffer for 24 hours and post fixed in $2 \%$ osmium tetra oxide in phosphate buffer for one hour. Ultrathin sections (80-90) were stained by uranyl acetate and lead acetate. Processing was done in TEM lab-National Cancer Institute (NCI).

\section{III- Statistical analysis:}

The Statistical Package for the Social Science (SPSS) was used for data analysis. The data obtained were summarized as means and standard deviations and compared using one way analysis of variance (ANOVA). $p$-values $<0.05$ was considered statistically significant, while $p<0.01$ was considered statistically highly significant.

\section{Results}

Light microscopic results:

Hematoxylin and Eosin results:

Group I and Group II (normal and sham control group):

Light microscope examination of both control and sham control groups revealed similar histological picture; the muscle fibers appeared branching and anastomosing running in different directions. The cardiac myocyte exhidited one or more oval to rounded vesicular nucleus adjoining the cell surface membrane. Also flat fibroblast with spindle shaped nucleus was found in the interstitial tissue Fig. (1).

\section{Group III (cisplatin treated group):}

Animal specimens of this group revealed histological changes in the form of loss of branching and anastomosing pattern of myocardium and complete loss of normal architecture of myocardium with widening of spaces of variable sizes inbetween muscle fibers Fig. (2). Mononuclear cellular infiltration, rupture of muscle membrane with extrusion of nucleus outside were appeared. Vascular changes in the form of dilated capillary, engorged blood vessel and extravasation of red blood cells were also encountered Fig. (3).

Group IV (cisplatin and qurecetine treated group):

Most of the myocardium in $\mathrm{H} \& \mathrm{E}$ sections from rats of this group appeared nearly normal as that in the control group. On other hand, some cardiac muscle fibers appeared slightly disorganized with mild spacing. Few pyknotic nuclei were encountered Fig. (4).

Masson's trichrome results:

Group I and Group II (normal and sham control group):

Masson's trichrome sections illustrated minimal amount of collagen in-between the cardiac muscle fibers, mainly around blood vessels Fig. (5).

\section{Group III (cisplatin treated group):}

Masson's trichrome sections showed increase in collagen deposition around engorged dilated blood vessel Fig. (6).

\section{Group IV (cisplatin and querectine treated group):}

Masson's trichrome sections revealed minimal collagen fibers were seen in-between myocardial fibers compared with the Group III Fig. (7).

\section{Immunohistochemical results:}

Group I and Group II (control and sham control groups):

Examination of the left ventricular sections of the control group stained with anti- $\alpha$-smooth muscle actin antibody revealed negative immunoreactivity in the myocardium Fig. (8).

\section{Group III (cisplatin treated group):}

Myocardial sections of the cisplatin group (Group III) stained with anti- $\alpha$-smooth muscle actin antibody showed positive immunoreactivity in the branched myofibroblasts Fig. (9).

\section{Group IV (cisplatin and querectine group):}

Myocardial sections of the Group IV stained with anti- $\alpha$-smooth muscle actin antibody showed minimal positive immunoreactivity in the myofibroblasts and in the smooth muscle fibers of the blood vessels Fig. (10).

\section{Electrone microscopic results:}

Group I and Group II (normal and sham control group):

Ultra structural examination showed normal structure of cardiomyocytes in the form of vesicular euchromatic nuclei and abundant electron dense mitochondria with normal cristal pattern, $\mathrm{Z}$ lines (line of meeting of actin and myosin filaments) were demonstrated Fig. (11).

\section{Group III (cisplatin treated group):}

Electron microscopic examination showed disruption and vaculotion of myofibrils, the nuclei 
of cardiomyocyte showed marginated nuclear chromatin. Mitochondria showed variability in size and shape, enlargement (ballooning) with disturbed cristal pattern Figs. $(12,13)$.

\section{Group IV (cisplatin and querectine treated group):}

Ultrastructural examination showed almost the same histological picture as with of the control group regarding the architecture of myocardium with demarcated $\mathrm{Z}$ lines and normal euchromatice nucleus with nucleolus inside. Mitochondria appear normal with intact cristae Fig. (14).

\section{Histomorphometric and statistical results:}

A- Statistical study of the mean area percentage of collagen fibers: The mean area percentage of the collagen fibers of Group III showed highly significant increase in its value $(p \leq 0.01)$

Table (1): Mean area \% of collagen fibers among the studied groups.

\begin{tabular}{lc} 
Groups & $\begin{array}{r}\text { Mean } \pm \text { SD of mean area \% of collagen fibers } \\
\text { (Masson's trichrome stain) }\end{array}$ \\
\hline Group I & $0.93^{\mathrm{b}} \pm 0.26$ \\
Group II & $0.85^{\mathrm{b}} \pm 0.27$ \\
Group III & $12.0^{\mathrm{a}} \pm 1.33$ \\
Group IV & $4.19^{\mathrm{a}}, \mathrm{b} \pm 1.31$ \\
\hline
\end{tabular}

Results are expressed as mean \pm standard deviation. $n=10$.

Multiple comparisons were accomplished using one way ANOVA followed by Tukey-Kramer as a post-ANOVA test. $p$-value $\leq 0.05$ considered statistically significan.

a: Significantly different from control group (Group I,II).

b: Significantly different from Cisplatin (Group III).

\begin{tabular}{lccc} 
Comparison & Difference & $\mathrm{q}$ & $p$-value \\
\hline Group I vs Group II & 0.08000 & 0.2657 & 0.9 \\
Group I vs Group III & -11.070 & 36.770 & 0.001 \\
Group I vs Group IV & -3.260 & 10.828 & 0.001 \\
Group II vs Group III & -11.150 & 37.036 & 0.001 \\
Group II vs Group IV & -3.340 & 11.094 & 0.001 \\
Group III vs Group IV & 7.810 & 25.942 & 0.001 \\
\hline
\end{tabular}

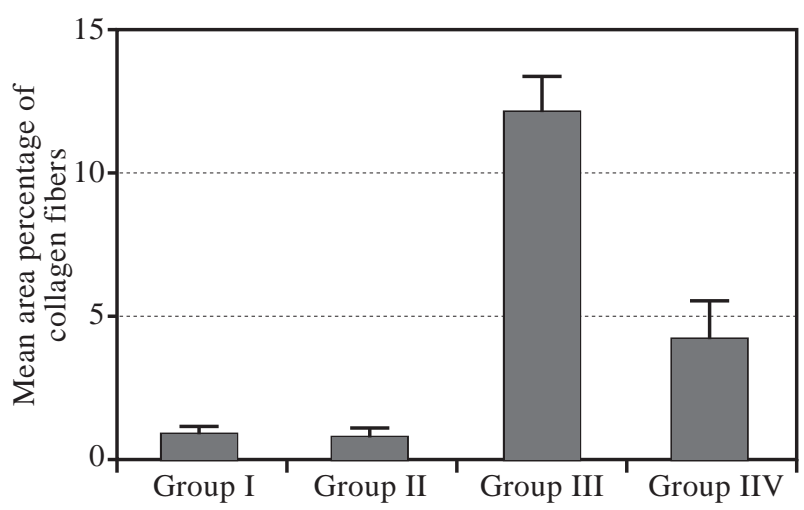

Histogram (1): Mean area \% of collagen fibers among the studied group. compared with the corresponding control group. The mean value of the area percentage of the collagen fibers of Group III increased significantly in comparison with Group IV. There was statistically significant difference between Group I and Group IV (Tables 1) and Histogram (1).

B- Statistical study of the area $\%$ of immune reaction of $\alpha$ SMA: The mean area $\%$ of $\alpha$-SMA immunopositive cells showed no significant difference among the control group (Group I), (Group II). While the cisplatin treated group (Group III) resulted in significant increase $(p<$ $0.05)$ in the mean area $\%$ of the $\alpha$-SMA immunoreactivity as compared to Groups I, II \& IV. There was statistically significant difference between Group I and Group IV (Tables 1) and Histogram (1).

Table (2): Mean area $\%$ of $\alpha$-SMA immunopositive cells among the studied groups.

\begin{tabular}{lc}
\hline Groups & $\begin{array}{c}\text { Mean } \pm \text { SD of mean area } \% \text { of } \alpha \text {-SMA } \\
\text { immunopositive cells }\end{array}$ \\
\hline Group I & $0.26^{\mathrm{b}} \pm 0.02$ \\
Group II & $0.39^{\mathrm{b}} \pm 0.06$ \\
Group III & $5.76^{\mathrm{a}} \pm 0.69$ \\
Group IV & $1.41^{\mathrm{a}}, \mathrm{b} \pm 0.31$ \\
\hline
\end{tabular}

Results are expressed as mean \pm standard deviation. $\mathrm{n}=10$.

Multiple comparisons were accomplished using one way ANOVA followed by Tukey-Kramer as a post-ANOVA test. $p$-value $\leq 0.05$ considered statistically significant.

a: Significantly different from control group (Group I,II).

b: Significantly different from Cisplatin (Group III).

\begin{tabular}{lclc} 
Comparison & Difference & \multicolumn{1}{c}{$\mathrm{q}$} & $p$-value \\
\hline Group I vs Group II & 0.2210 & 1.841 & 0.8 \\
Group I vs Group III & -5.500 & 45.825 & 0.001 \\
Group I vs Group IV & -1.150 & 9.582 & 0.001 \\
Group II vs Group III & -5.721 & 47.667 & 0.001 \\
Group II vs Group IV & -1.371 & 11.423 & 0.001 \\
Group III vs Group IV & 4.350 & 36.244 & 0.001 \\
\hline
\end{tabular}

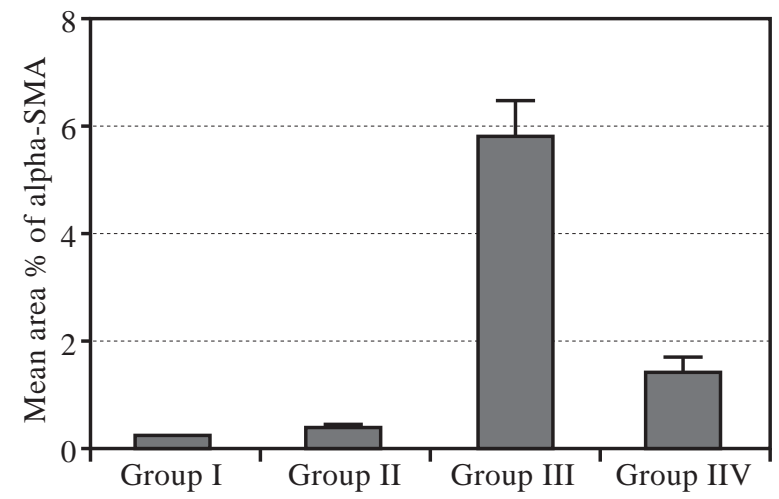

Histogram (2): Mean area $\%$ of $\alpha$-SMA immunopositive cells among the studied groups. 


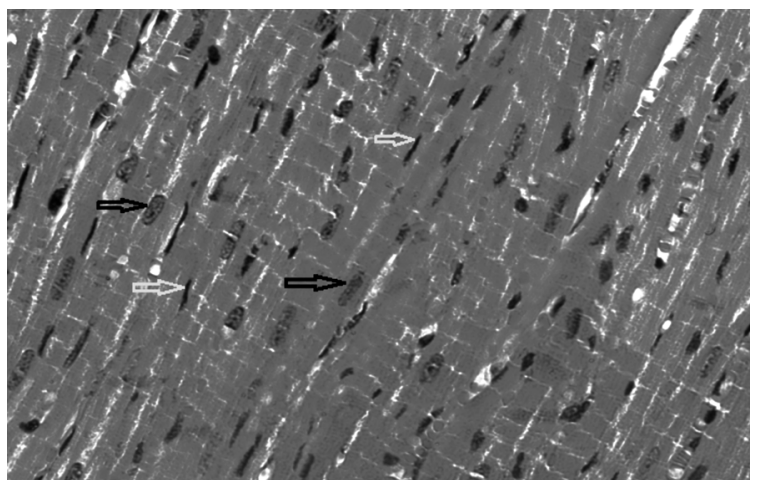

Fig. (1): A photomicrograph of section of left ventricle of control rat revealing normal architecture of myocardium with normal rounded to oval nuclei adjoining the cell surface membrane (blak arrows) and spindle shaped nuclei of fibroblast in the interstitial tissue in-between (green arrows). (Hx. \& E. X400)

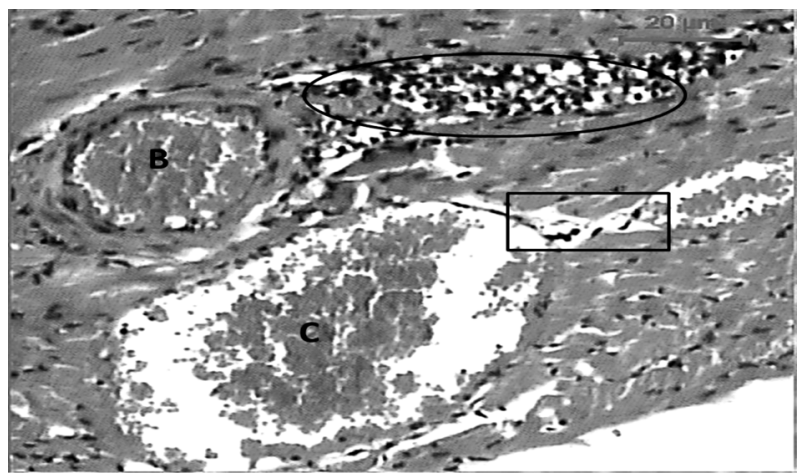

Fig. (3): A photomicrograph of section of left ventricle of micrograph Group III displaying loss of normal architecture of myocardium, mononuclear cellular infiltration (oval), engorged blood vessel (B), and dilated capillary $(\mathrm{C})$ and extrusion of nucleus outside (rectangle). (Hx. \& E. X400).

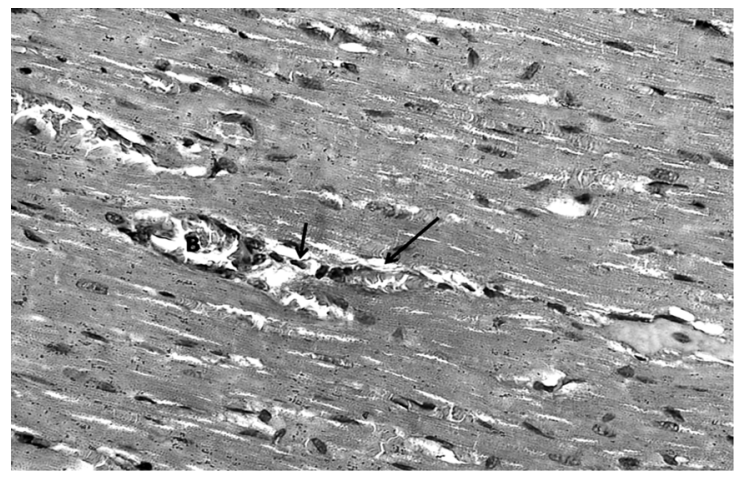

Fig. (5): A photomicrograph of section of left ventricle of Group I (normal control) displaying normal architecture of myocardium with minimal collagen deposition (arrows) around blood vessels. (M.T. X400).

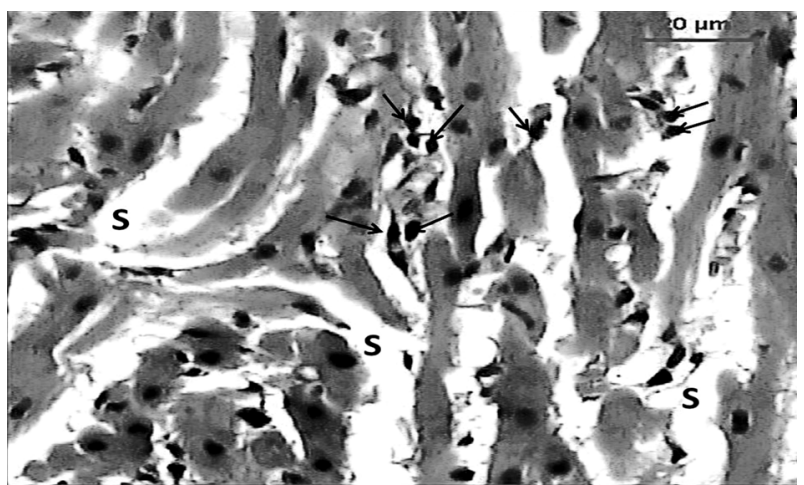

Fig. (2): A photomicrograph of section of left ventricle of Group III revealing complete loss of normal architecture of myocardium, widening of spaces in between muscle fibers (s) and extracellular nuclear extrusion (arrows). (Hx. \& E. X400).

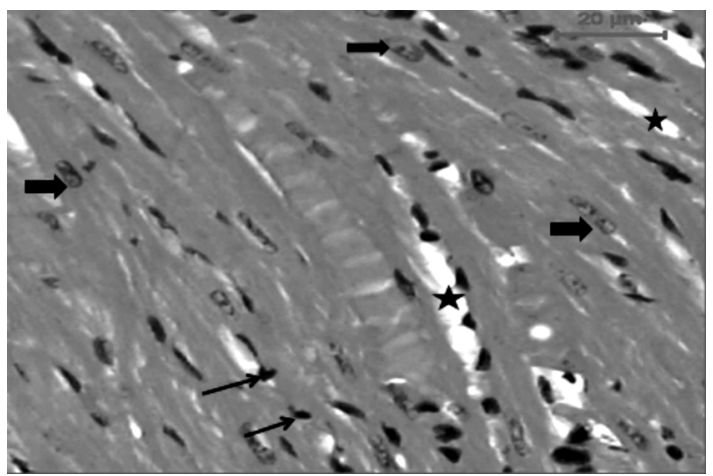

Fig. (4): A photomicrograph of section of left ventricle of Group IV showing almost normal architecture of myocardium with normal vesicular nucleus (thick arrows). Few scattered widening spaces inbetween muscle fibres $(*)$ and few pyknotic nucleus (thin arrows) were appeared. (H \& E X400).

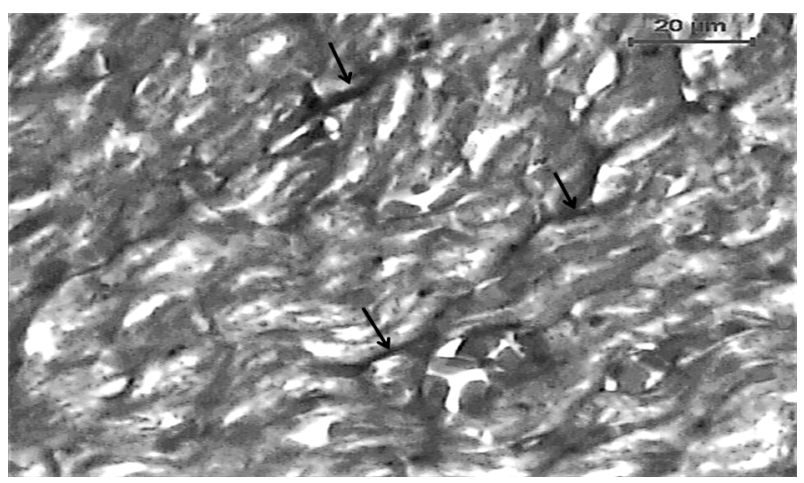

Fig. (6): A photomicrograph of section of left ventricle of Group III A showing disruption of normal architecture of myocardium with increase amount of collagen fibres deposition (arrows). (M.T. X400). 


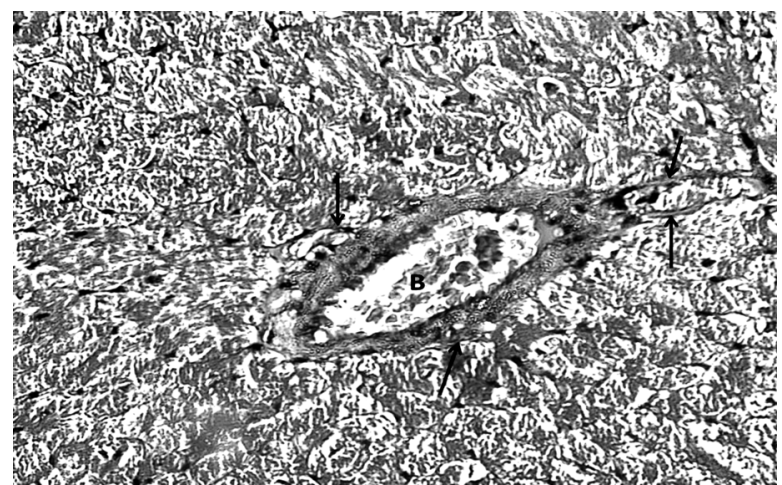

Fig. (7): A photomicrograph of section of left ventricle of Group IV displaying decrease the amount of collagen fibres deposition comparing with Group III. (M.T. X400).

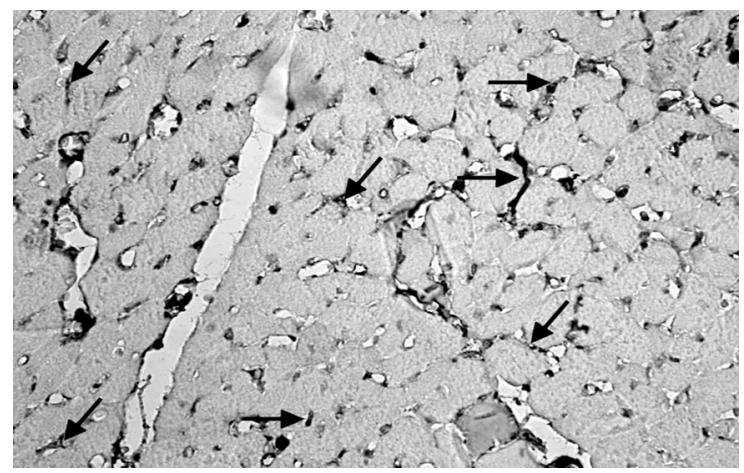

Fig. (9): A Photomicrograph of a section in the left ventricle of Group III stained for $\alpha$-SMA showing brown discoloration (positive immunoreactivity) detected in the myofibroblasts (arrows). (Anti- $\alpha$-SMA X400).

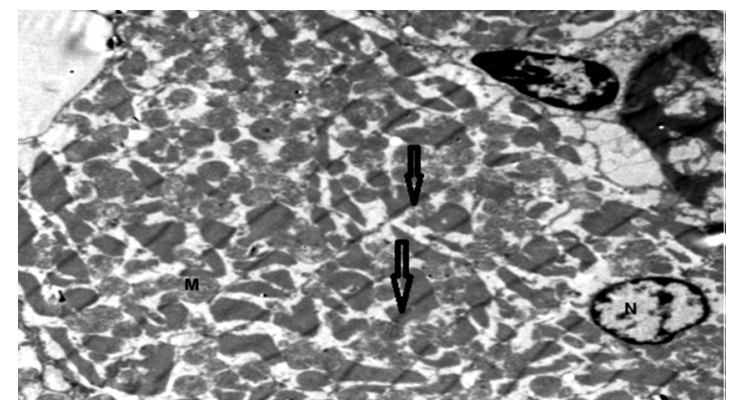

Fig. (11): An electron micrograph of a myofibrils of left ventricle of control group revealing regular arrangement of cardiac muscle fibers with regular $\mathrm{Z}$ lines (arrows), normal vesicular, euchromatic nuclei $(\mathrm{N})$, and normal Mitochondria (M) are seen between the myofibrils. (TEM X1000).

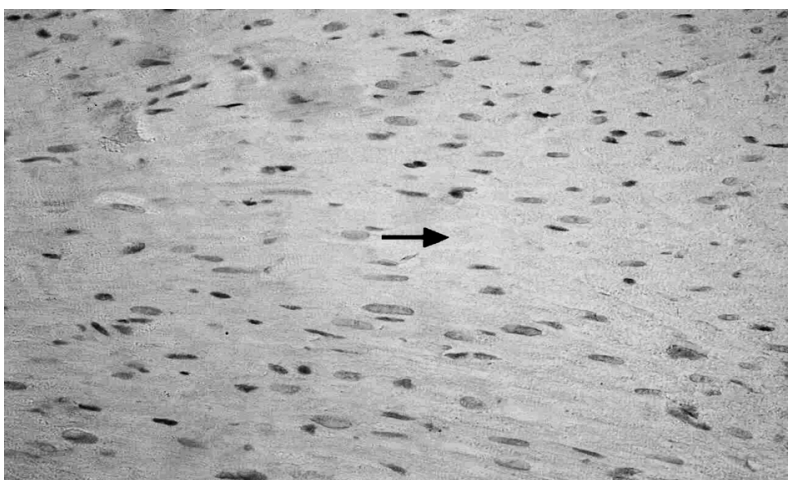

Fig. (8): A photomicrograph of section of left ventricle of control group stained for $\alpha$-SMA showing negative immunoreactivity in the myocardium (arrow). (Anti$\alpha$-SMA X400).

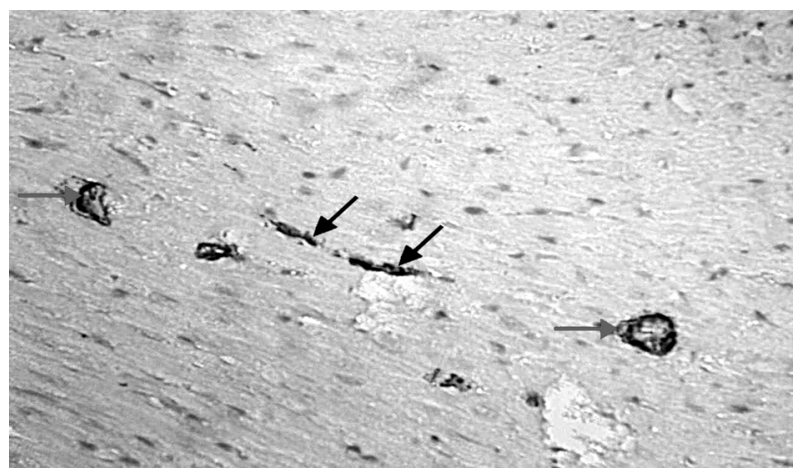

Fig. (10): A Photomicrograph of a section in the left ventricle of Group IV stained for $\alpha$-SMA showing minimal positive immunoreactivity detected in the myofibroblasts (black arrows) and in the smooth muscle fibers of the blood vessels (blue arrows) (Anti- $\alpha-$ SMA X400).

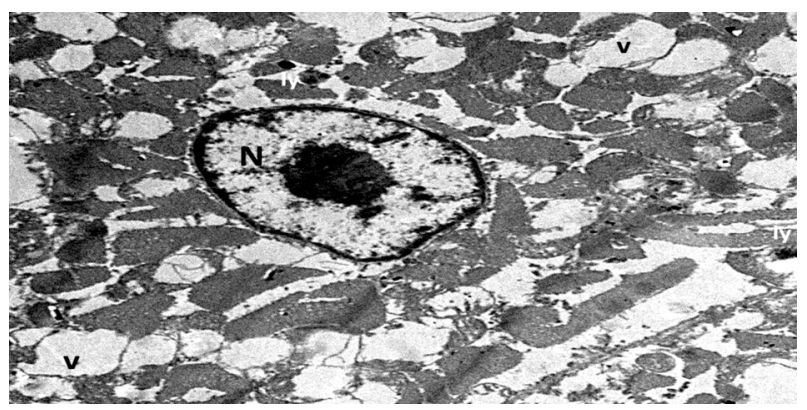

Fig. (12): An electron micrograph of a myofibrils of left ventricle of Group III revealing disruption and Vaculation ( $\mathrm{v}$ ) of myofibrils and marginated nuclear chromatin (N). (TEM X3000). 


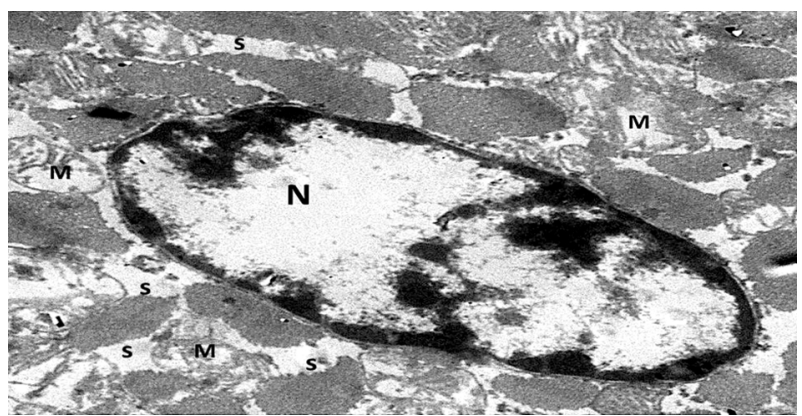

Fig. (13): An electron micrograph of myofibrils of left ventricle of Group III showing, marginated nuclear chromatin $(\mathrm{N})$, mitochondria are swollen with disrupted cristal pattern (M) and vaculated spaces (s). (TEM X5000).

\section{Discussion}

Cisplatin induced cardiotoxic effects including: Angina [16], acute myocardial infarction [17], thromboembolic events [18], hypertension [19], myocarditis, pericarditis and severe congestive cardiomyopathy [21]. This cardiotoxic effects can be range from simple ECG changes to death [20]. Clinical usage of cisplatin as an anti-tumoral agent was restricted due to increased amount of oxidative stress and apoptosis related to cardiotoxicity [21].

It has been established that excessive oxidative stress caused by either increased ROS production or inadequate antioxidant defense can lead to cardiac lesions [22].

It was demonstrated that cisplatin induces morphological and functional alterations in the heart leading to myocardial necrosis [23,24], similar observation was seen in the present work following cisplatin injection in the form of loss of branching and anastomosing pattern of myocardium, widening of spaces in-between muscle fibers and mononuclear cellular infiltration.

The reactive free radicals have the potential to injure the cardiomyocytes directly and may be also involved in triggering inflammatory cascades through the induction of cytokines regulating leucocyte trafficking [22], such finding could explain some of the mononuclear cell infiltrations seen following cisplatin injection.

In the current study, in cisplatin treated group using Masson trichrome stain there was an increase in collagen deposition around engorged dilated blood vessel and some collagen fibres appear inbetween myocardial fibers. These findings was confirmed by increased alpha smooth muscle actin expression.

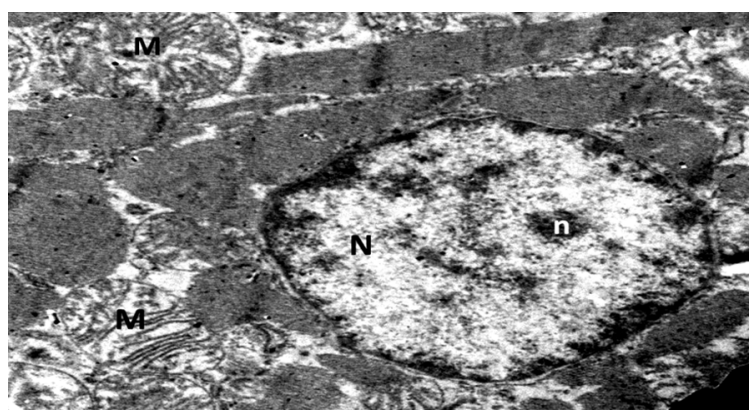

Fig. (14): An electron micrograph of myofibrils of left ventricle of Group IV showing almost normal architecture of cardiomyocytes with normal euchromatic nucleus $(\mathrm{N})$ and nucleolus (n). Most mitochondria (M) appear with normal cristal pattern. (TEM X4000).

In the present study, electrone microscopic examinations of cisplatin treated group revealed focal disruption of myofibrils, variability in size and shape of some mitochondria which appeared swollen, with disturbed cristal pattern. Nuclear changes were in the form of vacuolations with clogged marginated nuclear chromatine, electrolucent areas in nucleus. These was in agreement of Ma et al., [25] who reported that depressed cardiomyocyte contraction and mitochondrial abnormalities, increased endoplasmic reticulum stress and associated apoptosis caused cardiac damage following cisplatin treatment. In addition cardiomyocytes containing numerous mitochondria constitute an important site for cisplatin accumulation and this condition eventually can lead to mitochondrial DNA damage [26].

Pretreatment with qurectine in cisplatin treated rats reversed the cisplatin induced alterations in lipid metabolism. Qurectine was reported to augment the endogenous antioxidants, which is an important event that protects the heart and endothelial cells from oxidative injury. It is already reported that Qurectine is the potent scavenger of ROS and antilipoperoxidative agent that inhibits the oxidation of LDL-C, which prevent endothelial cell injury induced by oxidized LDL-C [27]. In myofibril impairment observation, no significant difference has been observed between control and qurectine pre-treated groups. This histological finding indicates that qurectine is capable of preventing the myofibril damage induced by cisplatine. Therefore, it may be suggested that qurectine might inhibit cisplatin-induced cardiac damage.

The following mechanisms have been proposed for the antioxidant effects of qurectine: [1] Being a direct antioxidant, Qurectine could quench and detox-ify several reactive intermediates, like 
hypochlorous acid $(\mathrm{HOCl})$ generated by myeloperoxidase, nitric oxide, $\mathrm{H}_{2} \mathrm{O}_{2}$, and hydroxyl radical, [2]. As an indirect antioxidant, qurectine could prevent the changes in membrane permeability due to oxidative injury via intercalating into the membrane and stabilizing it [28]. Renugadevi and Miltonprabu [29] reported that the membrane stabilizing effect of qurectine was linked to an action on permeability of ions and water.

\section{Conclusion:}

This study demonstrated that querectine had a significant effect in protection of the heart against myocardial histological changes induced by cisplatin.

\section{References}

1- PABLA and DONG: Cisplatin nephrotoxicity: Mechanisms and renoprotective strategies. Kidney Int.; 73: 994-1007, 2008.

2- YOUSEF M.I., SAAD A.A. and EL-SHENNAWY L.K.: Protective effect of grape seed proanthocyanidin extract against oxidative stress induced by cisplatin in rats. Food Chem. Toxicol. Jun.; 47 (6): 1176-83, 2009.

3- CHIRINO Y.I. and PEDRAZA-CHAVERRI J.: Role of oxidative and nitrosative stress in cisplatin-induced nephrotoxicity. Exp. Toxicol. Pathol.; 61: 223-42, 2009.

4- MORA L.O., ANTNNES L.M., FRANCESCATO H.D. and BIANCHI M.: The effects of oral glutamine on cisplatin induced nephrotoxicity in rats. Pharmacol. Res.; 47: 517-22, 2003.

5- DEVRIM E., CETIN R., KILICOGLU B., AVCI A., CANDIR O. and DURAK I.: Cisplatin impairs antioxidant system and causes oxidation in rat kidney tissues: Possible protective roles of natural antioxidant foods. J. Appl. Toxicol.; 26 (1): 42-6, 2006.

6- KUHAD A., TIRKEY N., PILKHWAL S. and CHOPRA $\mathrm{K}$.: Renoprotective effect of spirulina fusiformis on cisplatin-induced oxidative stress and renal dysfunction in rat. Ren. Fail.; 28 (3): 247-54, 2006.

7- DICKEY D.T., WU Y.J., MULDOON L.L. and NEUWELT E.A.: Protection against cisplatin induced toxicities by $\mathrm{N}$-acetylcysteine and sodium thiosulfate as assessed at the molecular, cellular and in vivo levels. J. Pharmacol. Exp. Ther.; 314: 1052-8, 2005.

8- TSURUYA K., TOKUMOTO M., NINOMIYA T., HIRAKAWA M., MASUTANI K., TANIGUCHI M., et al.: Antioxidant ameliorates cisplatin-induced renal tubular cell death through inhibition of death receptor mediated pathways. Am. J. Physiol. Renal. Physiol.; 285: F208F218, 2003.

9- GIBELLINI L., PINTI M., NASI M., MONTAGNA J.P., De BIASI S., ROAT E., et al.: Quercetin and cancer chemoprevention. Evid Based Complement Alternat Med.; 591356, 2011.

10- MORALES J., GÜNTHER G., ZANOCCO A.L. and LEMP E.: Singlet oxygen reactions with flavonoids. A theoretical-experimental study. PLoS ONE; 7: e40548, 2012.
11- ERTUĞ P.U., AYDINOGLU F., GORUROGLU OZTURK O., SINGIRIK E. and ÖGÜLENER N.: Comparative study of the quercetin, ascorbic acid, glutathione and superoxide dismutase for nitric oxide protecting effects in mouse gastric fundus. Eur. J. Pharmacol.; 698: 37987, 2013.

12- FILIPE P., MORLIÈRE P., PATTERSON L.K., HUG G.L., MAZIÈRE J.C. and FREITAS J.P.: Oxygen-copper (II) interplay in the repair of semi-oxidized urate by quercetin bound to human serum albumin. Free Radic. Res.; 38: 295-301, 2004.

13- KYAW M., YOSHIZUMI M., TSUCHIYA K., IZAWA Y., KANEMATSU Y. and TAMAKI T.: Atheroprotective effects of antioxidants through inhibition of mitogenactivated protein kinases. Acta Pharmacol. Sin.; 25: 97785, 2004.

14- ANGELONI C., SPENCER J.P., LEONCINI E., BIAGI P.L. and HRELIA S.: Role of quercetin and its in vivo metabolites in protecting $\mathrm{H} 9 \mathrm{c} 2$ cells against oxidative stress. Biochimie; 89: 73-82, 2007.

15- MOJZISOVÁ G., SARISSKÁ M., MIROSSAY L., MARTINKA P. and MOJZIS J.: Effect of flavonoids on daunorubicin-induced toxicity in $\mathrm{H} 9 \mathrm{c} 2$ cardiomyoblasts. Phytother. Res.; 23: 136-9, 2009.

16- ADAL1 F., YUCEL G., AHMET K., YASEMIN Y., GULAY O., CIGDEM O., KAMIL T., et al.: Effects of thymoquinone against cisplatin-induced cardiac injury in rats. Acta Cirúrgica Brasileira-Vol. 31 (4): 271-7, 2016.

17- LIANG W., LUO Z., GE S., LI M., DU J., YANG M., et a.: Oral administration of quercetin inhibits bone loss in rat model of diabetic osteopenia. Eur. J. Pharmacol.; Nov. 16; 670 (1): 317-24, 2011.

18- KHAN S., CHEN C.L., BRADY M.S., PARAMESWARAN R., MOORE R., HASSOUN H.H., et al.: Unstable angina associated with cisplatin and carboplatin in a patient with advanced melanoma. J. Clin. Oncol. Jun. 20; 30 (18): e163-4. PMID: 22585705, 2002.

19- RYBERG M.: Recent advances in cardiotoxicity of anticancer therapies. Am. Soc. Clin. Oncol. Educ. Book; 5559. PMID: 24451795, 2012.

20- MOORE R.A., ADEL N., RIEDEL E., BHUTANI M., FELDMAN D.R., TABBARA N.E., et al.: Soff G, Parameswaran R, Hassoun H. High incidence of thromboembolic events in patients treated with cisplatin-based chemotherapy: A large retrospective analysis. J. Clin. Oncol.; Sep. 1; 29 (25): 3466-73, 2011.

21- AMIT L., BEN-AHARON I., TICHLER T., INBAR E., SULKES A. and STEMMER S.: Cisplatin-induced posterior reversible encephalopathy syndromebrief report and review of the literature. J. Behav. Brain. Sci.; 2 (1): 97-101, 2012.

22- DOLCI A., DOMINICI R., CARDINALE D., SANDRI M.T. and PANTEGHINI M.: Biochemical markers for prediction of chemotherapyinduced cardiotoxicity: Systematic review of the literature and recommendations for use. Am. J. Clin. Pathol. Nov.; 130 (5): 688-95. PMID: 18854260, 2008.

23- OZCAN T., CIRIT A. and KIYKIM A.: Recurrent complete atrioventricular block during cisplatin infusion: A case report. J. Clin. Exp. Cardiol.; 2: 151, 2011. 
24- LOWENSTEIN C.: Exogenous Thioredoxin Reduces Inflammation in Autoimmune Myocarditis. Circulation; 110: 1178-9, 2004

25- FAHRI A., YUCEL G., AHMET K., YASEMIN Y., GULAY O., CIGDEM O., et al.: Effects of thymoquinone against cisplatin-induced cardiac injury in rats Acta Cirúrgica Brasileira; Vol. 31 (4) 2016-271, 2016.

26- QINGHUA D., LONG C., QUNWEI L., SHERVEN S., LEI L., SACHIO M., et al.: Quercetin attenuates doxorubicin cardiotoxicity by modulating Bmi-1 expression. British Journal of Pharmacology; 171: 4440-54, 2014.

27- MA H., JONES K.R., GUO R., XU P., SHEN Y. and REN J.: Cisplatin compromises myocardial contractile function and mitochondrial ultrastructure: Role of endoplasmic reticulum stress. Clin. Exp. Pharmacol. Physiol.; 37 (4): 460-5. PMID: 19878217, 2010.

28- QIAN W., NISHIKAWA M., HAQUE A.M., HIROSE
M., MASHIMO M., SATO E. and INOUE M.: Mitochondrial density determines the cellular sensitivity to cisplatininduced cell death. Am. J. Physiol. Cell Physiol., Dec.; 289 (6): C1466-75, 2005

29- CHEN C.Y., MLLBURY P.E., LAPSLEY K. and BLUMBERG J.B.: Flavoniods from almond skins are bioavailable and act synergistically with vitamins $\mathrm{C}$ and $\mathrm{E}$ to enhance hamster and human LDL resistance to oxidation. J. Nutr.; 135: 1366-73, 2005.

30- PAVANATO A., TUNON M.J., SANCHEZ-CAMPOS S., MARRONI C.A., LLESUY S., GONZALEZ-GALLEGO J., et al.: Effects of quercetin on liver damage in rats with carbon tetrachloride-induced cirrhosis. Dig. Dis. Sci.; 48: 824-9, 2003.

31- RENUGADEVI J. and MILTON S.: Quercetin protects against oxidative stress-related renal dysfunction by cadmium in rats. Exp. Toxicol. Pathol.; 62: 471-81, 2010.
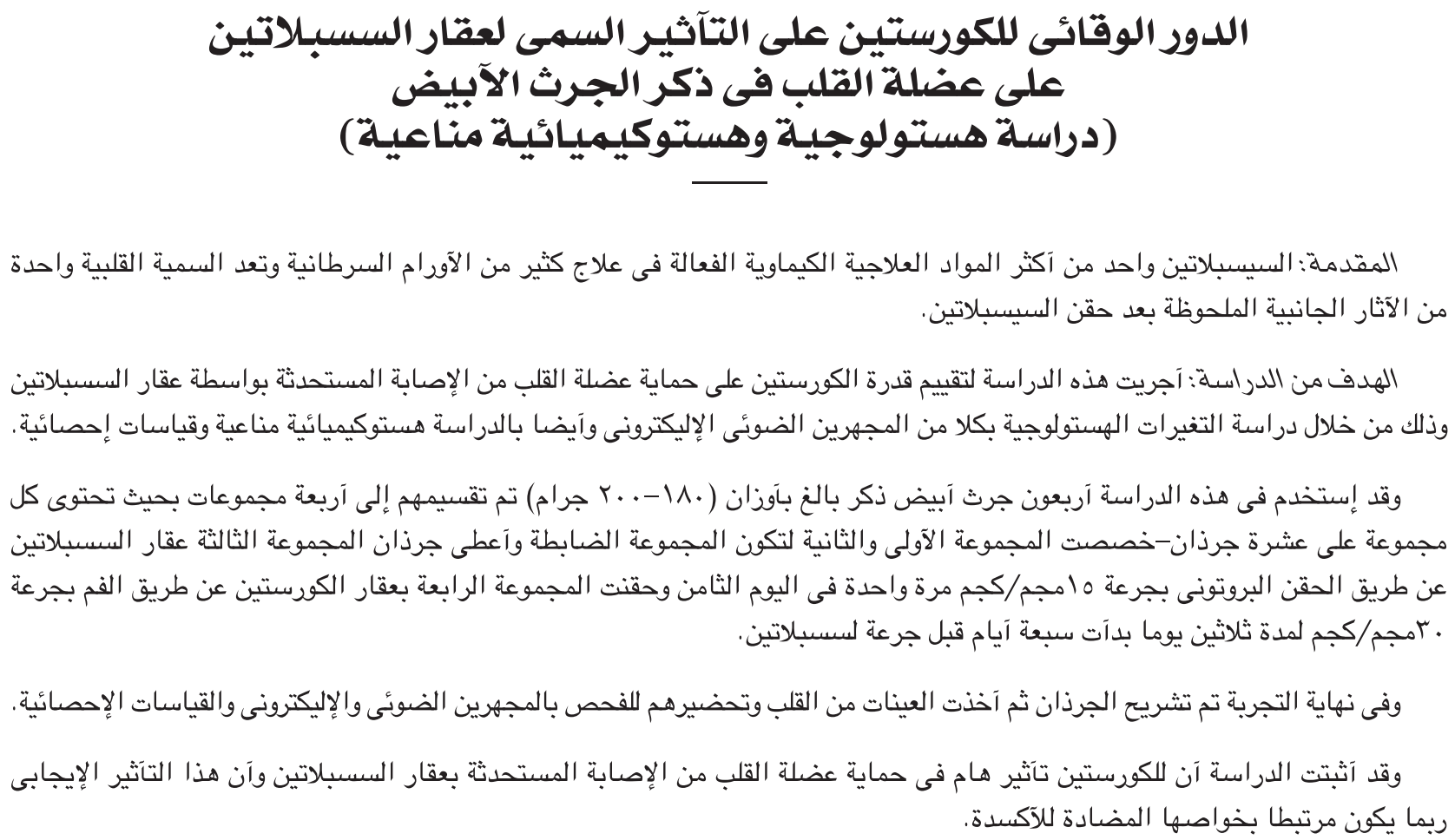